\title{
Auditoría ambiental del manejo de residuos sólidos de la ciudad de Granada, Nicaragua
}

\author{
M.Sc. Izamara Carolina Vega Aguirre \\ Facultad de Ciencias e Ingeniería \\ UNAN-Managua \\ iza_vega@hotmail.com
}

Fecha de recepción: 13 de febrero, 2020 / Fecha de aceptación: 24 de febrero, 2020

https://doi.org/10.5377/torreon.v9i24.9726

Palabras clave: auditoría ambiental, manejo residuos, plan de acción, residuos peligrosos, residuos urbanos.

\section{RESUMEN}

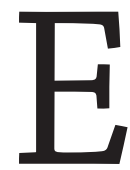

l estudio se enfoca en la realización de una auditoría ambiental que contribuirá al mejoramiento de las prácticas ambientales en el servicio de recolección de residuos sólidos que ofrece la Alcaldía de la ciudad de Granada, diagnosticando todo el proceso de recolección, tratamiento y disposición final de los residuos sólidos no peligrosos generados, lo que permitirá implementar un plan de acción y fortalecer el manejo de los residuos sólidos, a través de una guía de seguimiento de las acciones a cumplir al mejoramiento ambiental y una evaluación objetiva de los elementos del sistema de recolección, tratamiento y disposición final de los mismos, de esta manera se minimizarán o se pretende minimizar los riesgos de contaminación ambiental por la realización de actividades que por su naturaleza constituyen un riesgo potencial para el ambiente.

\section{INTRODUCCIÓN}

Uno de los principales factores que influyen en el éxito de un lugar de interés turístico es el aseo y limpieza del sitio. Los elementos naturales, culturales o históricos que son parte principal de los atractivos turísticos, pueden ser disminuidos o desfavorecidos cuando se 
presentan situaciones de descuido o por falta de aseo, que inclusive pueden poner en riesgo la salud de los visitantes y habitantes del lugar.

De lo anterior, resaltó la importancia de la realización de una auditoría ambiental en el manejo de los residuos sólidos de la ciudad de Granada; para lo cual se realizó un diagnóstico, con la finalidad de poder conocer el estado actual del procesamiento, manipulación y la capacidad para proteger el medio ambiente y la salud pública. Esto ayudó a plantear acciones necesarias y adecuadas para el manejo de los residuos sólidos, que por una parte aseguren la eficiencia en la limpieza y por otro lado no interfieran en las actividades del día a día de la ciudad.

\section{MATERIALES Y MÉTODOS}

Para la ejecución de la auditoría ambiental, se realizaron tres etapas generales las cuales a su vez se dividieron en sub etapas. Las etapas principales fueron:

1. Etapa I: Recopilación y Sistematización de los datos

Esta etapa consistió en el levantamiento de información referente al manejo de los residuos sólidos de la ciudad teniendo como base los indicadores: Generación, Separación, Almacenamiento, Recolección, Transporte, Barrido y Disposición final.

Para la recopilación de la información se procedió en tres sub etapas:

a. Recopilación de información Primaria

Para la recopilación primaria se realizó entrevistas a los actores involucrados como son: Director de Servicios Municipales, Epidemiólogo del Hospital Japón-Nicaragua, Vigilante del puesto de transferencia "El Plantelito" y Vigilante del vertedero "La Joya". En las entrevistas se utilizaron cuestionarios con preguntas abiertas y cerradas.

b. Revisión de Información Secundaria

La revisión de información secundaria implicó la búsqueda y recopilación bibliográfica de la investigación antes referida.

c. Verificación in situ

En esta sub etapa se procedió a realizar visitas por parte del equipo auditor a las distintas localidades donde se involucran la generación de residuos como son: hospital, puestos de transferencias, mercado, playa, parques, plazas públicas, sector turístico, vertedero, barrios y cauces. 


\section{Etapa II: Identificación y Discusión de Hallazgos}

Con la información obtenida producto de la etapa I, se realizó un análisis de la misma y como consecuencia la identificación de hallazgos para su posterior discusión por parte del equipo auditor.

3. Etapa III: Elaboración de Informe Final

Como resultado de la Etapa II, se elaboró un informe final para proponer posibles recomendaciones que conlleven a mejorar el manejo de los residuos sólidos no peligrosos.

\section{RESULTADOS Y DISCUSIÓN}

\section{Manejo Integral de los Residuos Sólidos}

Para el análisis del manejo de los residuos sólidos de la ciudad de Granada se analizaron los dos tipos de servicio: aseo ordinario o regular, servicio de aseo extraordinario o servicio especial, además del manejo del vertedero "La Joya" de la ciudad.

\section{Aseo Ordinario o Regular}

\section{Mercado Municipal}

En la actualidad el mercado está conformado por un área de terreno de $11,700 \mathrm{~m}^{2}$ y el área construida de 9,192 $\mathrm{m}^{2}$, cuenta con 1850 comerciantes formales y 480 comerciantes informales, estos últimos varían en dependencia de la época del año, transcurren aproximadamente unas 2000 personas a diario por todo el mercado y sus alrededores.

La gerencia del mercado cuenta con un personal propio de recolectores de residuos, los cuales están divididos en 7 zonas: Patio 1 y 2, Pescado, Ropa y calzado, Comercio, Países bajos, Campana y Mombacho.

En las afueras del mercado municipal se cuenta con un puesto de trasferencia de residuos sólidos llamado "El Plantelito", el cual posee un área de $746 \mathrm{~m}^{2}$, que recepciona los residuos sólidos recolectados de la limpieza del mercado y las calles cercanas al mismo. Según los registros del sitio, hace cinco años se recepcionaban 7.8 toneladas de residuos sólidos a la semana y actualmente, son más de ocho toneladas.

La frecuencia de traslado de los residuos al vertedero La Joya, son dos veces al día (7:15 am y 4:00 pm). Durante la recolección de los residuos en el puesto de transferencia los ayudantes de los camiones recolectores realizan la separación y clasificación de los residuos, con el fin de venderla posteriormente y repartir las ganancias entre los trabajadores del camión, es una forma en cómo se ayudan económicamente. 
"El Plantelito" cuenta con las condiciones necesarias de infraestructura como: portón de acceso, muro perimetral, acceso adoquinado, servicios higiénicos, energía eléctrica y agua potable; además de funcionar como puesto de trasferencia también funciona como bodega de almacenamiento de los carretones de recolectores de basura y de materiales de mantenimiento estructural del edificio del mercado.

\section{Hospital Japón-Nicaragua}

En el hospital existen dos tipos de residuos sólidos que se clasifican en peligrosos o biológicos infecciosos y los no peligrosos o comunes. El manejo de estos está a cargo de un epidemiólogo del Hospital.

Los residuos que son generados por partes de los usuarios, trabajadores, cafetines y cocina del hospital son: papeles, botellas plásticas, bolsas y cascaras de frutas. Estos residuos son recolectados dos veces al día en los distintos basureros ubicados en el Hospital y llevados al área de almacenamiento, estando en este lugar son colocados en contenedores en espera para que el camión de los residuos de la ciudad los recolecte.

\section{Recolección Casa a Casa}

La recolección casa a casa en la actualidad está cubriendo el 100\% de la zona urbana (97941 habitantes). A partir del mes de mayo del 2015 la recolección se hizo extensiva a la zona rural con una cobertura del $50 \%$ y con una frecuencia de un día a la semana. La recolección de residuos en el área rural es en: Posintepe, El Pochote, El Fortín, El Hormigón, Tepeyac y El Mamón, La Prusia, Kauloa, El Guayabo, Los Cocos, Osagay, Camino Real y El Paso.

La información obtenida por servicios municipales de Granada indica que el pago por este servicio por parte de la población es baja porque apenas cubre el $20.57 \%$ de los gastos totales del servicio de recolección de basura, el nivel de subsidio a la población brindado por la municipalidad alcanza el $80 \%$. Por lo que solucionar este problema es determinante para frenar el desgaste económico que significa invertir en una actividad que puede auto sostenerse.

Por otra parte, dentro del sistema domiciliar también se presta el servicio para la recolección de los residuos producidos por los supermercados: La Colonia, La Unión y dos Pali. Las empresas como: Chamorro, Ceguel, Zonas Francas, entre otras; ellas mismas se encargan del transporte de sus residuos al vertedero, donde se encuentra un supervisor del área de servicios municipales de la Alcaldía cuya función es llevar la cuenta de cuantas veces las empresas llegan a depositar basura, según a este registro es como se les cobra a las empresas por el servicio de disposición final de los residuos. 
Es importante mencionar que el supervisor solo lleva el control de las entradas y salidas pero no tiene un registro de la clasificación física o química de los residuos que llegan a dejar las empresas.

\section{Barrido de Calles}

El barrido de calles se encuentra priorizada principalmente para la zona central o turística con dos turnos de 6:00 am a 12:00 md y 12:00 md a 6:00 pm, la cobertura de barrido de calles es de 93\% con relación a las calles revestidas (pavimento y adoquín), esto debido a que los ciudadanos toman el compromiso de limpiar sus calles conforme son beneficiados por el programa "Calles para el Pueblo" (adoquinado) de sus vías de acceso a sus hogares. En el año 2016 se amplió el servicio de barrido de calles de 600 a 828 cuadras/día (23km de ampliación).

\section{Servicio de aseo extraordinario o servicio especial}

\section{Limpieza de Cauces y Tragantes}

La estrategia de limpieza consiste en realizarla antes del invierno con una cobertura de $17 \mathrm{~km}$ de los principales cauces que recorren la ciudad; luego de esta jornada cuenta con un plan de mantenimiento de los puntos críticos, esto se lleva a cabo en dependencia de las frecuencias y estragos de las lluvias. Esta actividad es realizada con 19 trabajadores y un supervisor.

Además, junto a la limpieza de cauces se realiza el mantenimiento de 360 tragantes y manjoles pluviales. Cabe mencionar que en los últimos tres años se han instalado más de 250 parrillas metálicas y/o planchetas de concretos.

\section{Plan Playa}

La Alcaldía se encarga de la limpieza de las vías de acceso al Centro Turístico, de los pequeños botaderos ilegales generados por la comercialización de cocos y otros alimentos y de los $400 \mathrm{~m}$ de la costa del lago frente al parque Azul hasta donde finaliza el malecón.

\section{Festividades}

Granada es partícipe de grandes festividades tanto del pueblo granadino, nacionales e internacionales como son: El festival internacional de la poesía, las procesiones tradicionales de Semana Santa, Fiestas Agostinas, Celebración de la novena de La Purísima, entre otros.

La estrategia tomada para estas eventualidades es la limpieza inmediata del lugar luego de transcurrir el evento, el número del personal con que cuenta para estas ocasiones va en dependencia del área que cubren las festividades, pero en promedio se cuenta con tres a diez barredores de calles. 
En la actualidad, al único sector industrial que la municipalidad le presta el servicio de recolección de basura es a las Zonas Francas ubicadas en el perímetro de la ciudad, los residuos de la Zona Franca se encuentran incluido en el recorrido de casa a casa; el pago por el servicio es dependiendo de la cantidad de viajes que se solicita.

\section{Análisis de Incremento de Basura}

Servicios municipales trabaja con proyecciones de un estudio realizado en 1997, por la Agencia Japonesa de Cooperación Internacional (JICA), en el cual establecen que el aumento anual de los residuos sólidos urbanos es de 1\% a como se puede observar en la tabla 1.

Tabla 1. Incremento de la tasa per cápita de generación de residuos sólidos

\begin{tabular}{|l|l|l|l|l|l|l|}
\hline \multicolumn{1}{|c|}{ Fuente } & \multicolumn{1}{c|}{ Unidad } & $\mathbf{2 0 1 3}$ & $\mathbf{2 0 1 4}$ & $\mathbf{2 0 1 5}$ & $\mathbf{2 0 1 6}$ & $\mathbf{2 0 1 7}$ \\
\hline Domiciliar & $\mathrm{kg} / \mathrm{hab} . / \mathrm{dia}$ & 0.84 & 0.85 & 0.86 & 0.87 & 0.88 \\
\hline Mercado Municipal & $\mathrm{kg} / \mathrm{hab} . / \mathrm{dia}$ & 3.52 & 3.55 & 3.59 & 3.62 & 3.66 \\
\hline Barrido de Calles & $\mathrm{kg} / \mathrm{h} a b . / \mathrm{dia}$ & 39.92 & 40.32 & 40.72 & 41.13 & 41.54 \\
\hline Comerciales & $\mathrm{kg} / \mathrm{h} a b . / \mathrm{dia}$ & 2.09 & 2.11 & 2.13 & 2.15 & 2.18 \\
\hline Restaurantes & $\mathrm{kg} / \mathrm{hab} . / \mathrm{dia}$ & 18.80 & 18.99 & 19.18 & 19.37 & 19.57 \\
\hline Institucionales & $\mathrm{kg} / \mathrm{hab} . / \mathrm{dia}$ & 0.11 & 0.12 & 0.12 & 0.12 & 0.12 \\
\hline
\end{tabular}

Fuente: Servios Municipales; Informe “Logros y Dificultades 2015”.

Por lo antes expuesto, en el año 2015 se realizó un muestreo piloto de la cantidad de residuos generados en la recolección domiciliar, lo que generó un resultado de $0.874 \mathrm{~kg} / \mathrm{habitante/}$ día; esto se logró con el apoyo económico de los Fondos para Proyectos de Investigación (FPI) de la UNAN- Managua.

\section{Plan de Acción}

El Programa de Manejo de Residuos Sólidos de la Ciudad fue diseñado para beneficiar al municipio. Para su adecuada ejecución, se requiere de la acción conjunta de los distintos sectores sociales tanto privados como públicos, siendo la Alcaldía el ente coordinador del mismo.

Las acciones del Plan de Manejo se pueden clasificar según el período de planificación en acciones de corto plazo: de 0 a 3 años (2017-2019), mediano plazo: de 3 a 5 años (2020-2023), largo plazo: de 6 a 10 años (2024- 2027).

Los plazos fueron escogidos según la prioridad de acción y del posible monto económico que en ellos se tienen que tener para su ejecución. Las acciones de corto plazo corresponden a 
las actividades de puesta en marcha del plan, las cuales son de vital importancia al ser el punto de partida y base para las acciones de mediano y largo plazo.

Tabla 2. Fortalecimiento de la Gestión Institucional

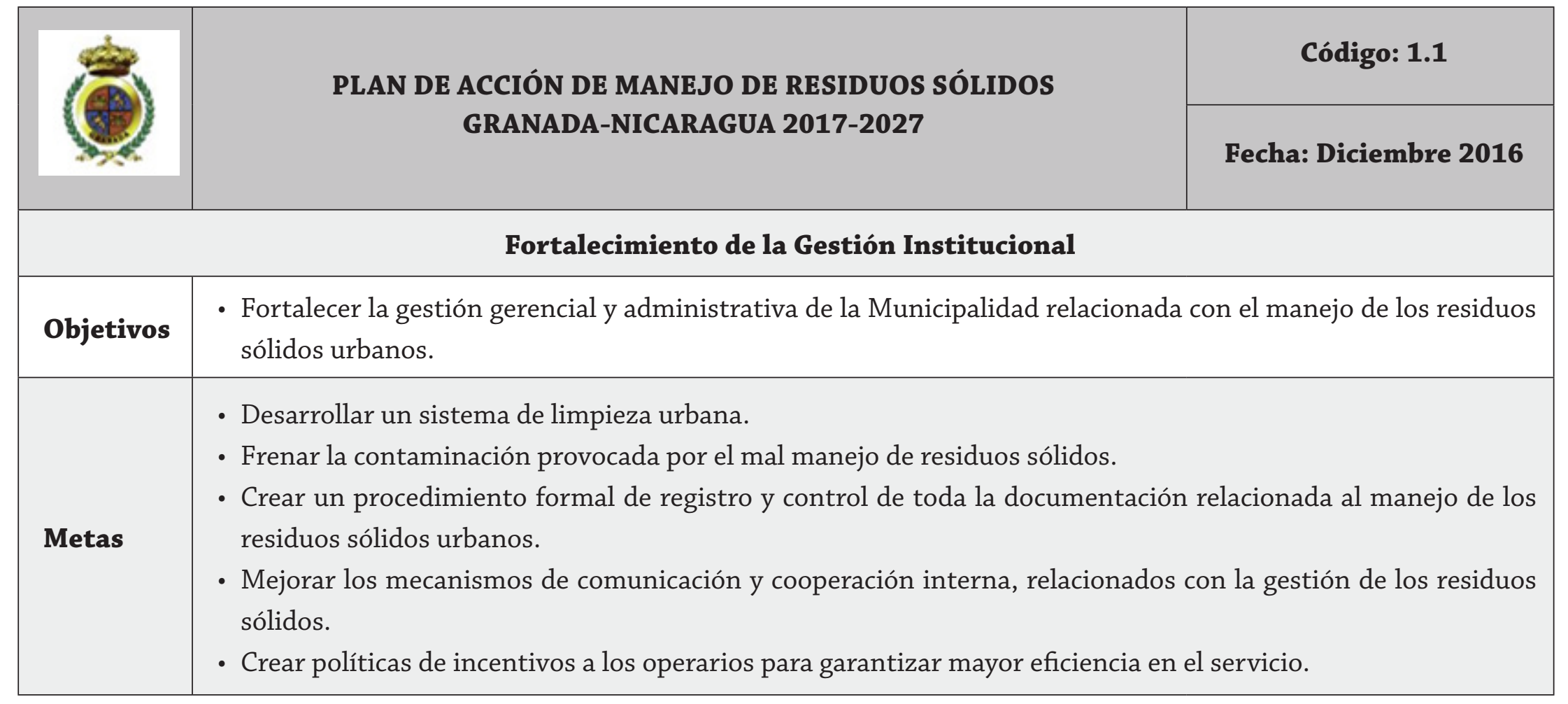

\begin{tabular}{|c|l|l|l|l|}
\hline \multicolumn{1}{|c|}{ No } & \multicolumn{1}{|c|}{ Acción } & \multicolumn{1}{c|}{ Plazo } & \multicolumn{1}{c|}{ Indicador } & \multicolumn{1}{c|}{ Responsable } \\
\hline \multirow{3}{*}{1} & $\begin{array}{l}\text { Actualizar e implementar el Plan } \\
\text { de Gestión Ambiental, con un } \\
\text { presupuesto asignado. }\end{array}$ & $2017-2023$ & $\begin{array}{l}\text { Documentación } \\
\text { aprobada y } \\
\text { divulgada }\end{array}$ & $\begin{array}{l}\text { Dirección Ambiental } \\
\text { Dirección de Servicios Mu- } \\
\text { nicipales }\end{array}$ \\
\hline
\end{tabular}




\begin{tabular}{|c|c|c|c|c|}
\hline No & Acción & Plazo & Indicador & Responsable \\
\hline 2 & $\begin{array}{l}\text { Actualizar el catastro de usua- } \\
\text { rios del servicio de recolección y } \\
\text { limpieza }\end{array}$ & 2018 y Cada dos años & $\begin{array}{l}\text { Documentos } \\
\text { del Registro } \\
\text { actualizados. }\end{array}$ & $\begin{array}{l}\text { Personal de Recaudación } \\
\text { Dirección de Finanzas, } \\
\text { Servicios Municipales }\end{array}$ \\
\hline 3 & $\begin{array}{l}\text { Elaborar de un plan de contingen- } \\
\text { cia frente al servicio de limpieza } \\
\text { pública }\end{array}$ & 2020-2027 & $\begin{array}{l}\text { Documentación } \\
\text { aprobada y } \\
\text { divulgada }\end{array}$ & $\begin{array}{l}\text { Dirección Ambiental } \\
\text { Dirección de Servicios } \mathrm{Mu}- \\
\text { nicipales }\end{array}$ \\
\hline 4 & $\begin{array}{l}\text { Actualizar y crear base de datos de } \\
\text { la caracterización Física y Peso de } \\
\text { los residuos sólidos }\end{array}$ & Cada dos años & $\begin{array}{l}\text { Documentación } \\
\text { Actualizada }\end{array}$ & $\begin{array}{l}\text { Dirección Ambiental } \\
\text { Dirección de Servicios } \mathrm{Mu}- \\
\text { nicipales }\end{array}$ \\
\hline 5 & $\begin{array}{l}\text { Instalar de un portón y cerca peri- } \\
\text { metral del vertedero }\end{array}$ & $2020-2023$ & Contrición & $\begin{array}{l}\text { Dirección de Servicios Mu- } \\
\text { nicipales }\end{array}$ \\
\hline 6 & $\begin{array}{l}\text { Elaborar Planes Sectoriales de } \\
\text { Manejo de Residuos Sólidos prin- } \\
\text { cipalmente en el sector Comercial, } \\
\text { turístico e industrial }\end{array}$ & 2018-2023 & $\begin{array}{l}\text { Documentos de } \\
\text { Planes Sectoria- } \\
\text { les elaborados }\end{array}$ & $\begin{array}{l}\text { Personal de Servicios Mu- } \\
\text { nicipales y Medio Ambien- } \\
\text { te, Sector Privado }\end{array}$ \\
\hline 7 & $\begin{array}{l}\text { Crear y aplicar indicadores para el } \\
\text { seguimiento y control del manejo } \\
\text { de residuos sólidos }\end{array}$ & $2020-2023$ & $\begin{array}{l}\text { Número de } \\
\text { indicadores } \\
\text { creados }\end{array}$ & $\begin{array}{l}\text { Dirección de Servicios Mu- } \\
\text { nicipales }\end{array}$ \\
\hline 8 & $\begin{array}{l}\text { Colocar recipientes en donde los } \\
\text { transeúntes depositen sus resi- } \\
\text { duos. }\end{array}$ & 2017-2019 & $\begin{array}{l}\text { Aprobación del } \\
\text { Estudio }\end{array}$ & $\begin{array}{l}\text { Alcalde, Director de Servi- } \\
\text { cios Municipales, Jefe de } \\
\text { Ornato y Limpieza }\end{array}$ \\
\hline 9 & $\begin{array}{l}\text { Digitalizar macros y micro rutas } \\
\text { de recolección y barrido de calles }\end{array}$ & 2024-2027 & Mapas Digitales & $\begin{array}{l}\text { Dirección de Servicios Mu- } \\
\text { nicipales }\end{array}$ \\
\hline
\end{tabular}




\begin{tabular}{|c|c|c|c|c|}
\hline No & Acción & Plazo & Indicador & Responsable \\
\hline 10 & $\begin{array}{l}\text { Adquirir carpas para cubrir los } \\
\text { residuos sobre los camiones reco- } \\
\text { lectores. }\end{array}$ & 2018-2023 & $\begin{array}{l}7 \text { carpas (para } \\
\text { cada uno de los } \\
\text { vehículos reco- } \\
\text { lectores) }\end{array}$ & $\begin{array}{l}\text { Director de Servicios } \mathrm{Mu}^{-} \\
\text {nicipales, Jefe de Ornato y } \\
\text { Limpieza }\end{array}$ \\
\hline 11 & $\begin{array}{l}\text { Desarrollar un estudio de Factibi- } \\
\text { lidad de nuevos puestos de trans- } \\
\text { ferencia en la ciudad. }\end{array}$ & 2020-2027 & $\begin{array}{l}\text { Documentación } \\
\text { Aprobada y } \\
\text { divulgada }\end{array}$ & $\begin{array}{l}\text { Dirección de Servicios } \\
\text { Municipales y Dirección } \\
\text { Ambiental }\end{array}$ \\
\hline 12 & $\begin{array}{l}\text { Realizar un estudio técnico-opera- } \\
\text { tivo para la actualización de rutas } \\
\text { de recolección de los residuos } \\
\text { urbanos y rurales. }\end{array}$ & 2017-2019 & $\begin{array}{l}\text { Documento del } \\
\text { Estudio }\end{array}$ & $\begin{array}{l}\text { Concejo Municipal, Direc- } \\
\text { ción de Servicios Muni- } \\
\text { cipales Jefe de Ornato y } \\
\text { Limpieza }\end{array}$ \\
\hline 13 & $\begin{array}{l}\text { Construir de una caseta de se- } \\
\text { guridad que preste los servicios } \\
\text { básicos (luz, agua, teléfono) en el } \\
\text { vertedero municipal. }\end{array}$ & $2020-2023$ & $\begin{array}{l}\text { Inauguración de } \\
\text { la caseta }\end{array}$ & $\begin{array}{l}\text { Dirección de Servicios Mu- } \\
\text { nicipales }\end{array}$ \\
\hline 14 & $\begin{array}{l}\text { Desarrollar un estudio de pre } \\
\text { factibilidad técnico-económica y } \\
\text { ambiental para la construcción de } \\
\text { un nuevo relleno sanitario. }\end{array}$ & $2018-2023$ & $\begin{array}{l}\text { Documentación } \\
\text { Aprobada y } \\
\text { divulgada }\end{array}$ & $\begin{array}{l}\text { Dirección de Servicios Mu- } \\
\text { nicipales }\end{array}$ \\
\hline 15 & $\begin{array}{l}\text { Desarrollar un plan de gestión } \\
\text { integral de residuos de manejo } \\
\text { especial }\end{array}$ & 2024-2027 & Plan de Gestión & $\begin{array}{l}\text { Dirección de Servicios Mu- } \\
\text { nicipales, Dirección Am- } \\
\text { bienta, MINSA y Gerencia } \\
\text { del Mercado }\end{array}$ \\
\hline
\end{tabular}




\begin{tabular}{|c|c|c|c|c|}
\hline No & Acción & Plazo & Indicador & Responsable \\
\hline 16 & $\begin{array}{l}\text { Elaborar de un Plan de cierre del } \\
\text { botadero, con la implementación } \\
\text { de prácticas que apunten al apro- } \\
\text { vechamiento de subproductos, } \\
\text { para reducir el impacto ambiental } \\
\text { y social }\end{array}$ & 2020-2023 & $\begin{array}{l}\text { Documentación } \\
\text { Aprobada y } \\
\text { divulgada }\end{array}$ & $\begin{array}{l}\text { Dirección de Servicios } \\
\text { Municipales y Dirección } \\
\text { Ambiental }\end{array}$ \\
\hline 17 & $\begin{array}{l}\text { Actualizar las tarifas de recolec- } \\
\text { ción y disposición final de los } \\
\text { residuos que permita una sosteni- } \\
\text { bilidad económica del servicio. }\end{array}$ & 2020-2023 & $\begin{array}{l}\text { Documentación } \\
\text { Aprobada y } \\
\text { divulgada }\end{array}$ & $\begin{array}{l}\text { Área de Contabilidad y } \\
\text { Dirección Ambiental }\end{array}$ \\
\hline 18 & $\begin{array}{l}\text { Equipar a los camiones un Boti- } \\
\text { quín de primeros auxilios. }\end{array}$ & 2017-2019 & Entrega anual & $\begin{array}{l}\text { Dirección de Servicios Mu- } \\
\text { nicipales }\end{array}$ \\
\hline 19 & $\begin{array}{l}\text { Comprar y entregar el equipo de } \\
\text { protección a los trabajadores de } \\
\text { recolección, transporte y disposi- } \\
\text { ción final de los residuos sólidos }\end{array}$ & Anual & $\begin{array}{l}\text { Recibos de en- } \\
\text { trega de equi- } \\
\text { pos }\end{array}$ & $\begin{array}{l}\text { Concejo Municipal, Perso- } \\
\text { nal de Servicios Municipa- } \\
\text { les }\end{array}$ \\
\hline 20 & $\begin{array}{l}\text { Adquirir e instalar una báscula en } \\
\text { el vertedero municipal }\end{array}$ & 2017-2019 & Báscula & $\begin{array}{l}\text { Dirección de Servicios } \mathrm{Mu}- \\
\text { nicipales }\end{array}$ \\
\hline
\end{tabular}


Tabla 3. Fortalecimiento del Marco Legal

\begin{tabular}{|c|c|c|}
\hline & \multirow{2}{*}{$\begin{array}{l}\text { PLAN DE ACCIÓN DE MANEJO DE RESIDUOS SÓLIDOS } \\
\text { GRANADA-NICARAGUA 2017-2027 }\end{array}$} & Código: 1.2. \\
\hline & & Fecha: Diciembre 2016 \\
\hline \multicolumn{3}{|c|}{ Fortalecimiento del Marco Legal } \\
\hline Objetivos & \multicolumn{2}{|c|}{$\begin{array}{l}\text { - Formular e implementar instrumentos legales para el fortalecimiento del marco legal municipal vinculado a la } \\
\text { gestión de los residuos sólidos urbanos. }\end{array}$} \\
\hline Metas & \multicolumn{2}{|c|}{$\begin{array}{l}\text { - Desarrollar un procedimiento formal para identificar y mantener actualizada la información respecto a las } \\
\text { disposiciones legales relacionadas al manejo de los residuos sólidos urbanos. }\end{array}$} \\
\hline
\end{tabular}

\begin{tabular}{|l|l|l|l|l|}
\hline \multicolumn{1}{|c|}{ No } & \multicolumn{1}{|c|}{ Acción } & \multicolumn{1}{c|}{ Plazo } & \multicolumn{1}{c|}{ Indicador } & \multicolumn{1}{c|}{ Responsable } \\
\hline \multirow{2}{*}{1} & $\begin{array}{l}\text { Revisar, actualizar y aplicar las Or- } \\
\text { denanzas Municipales que regulen } \\
\text { la gestión integral de los residuos } \\
\text { sólidos urbanos }\end{array}$ & 2017-2027 & $\begin{array}{l}\text { Número de } \\
\text { ordenanzas } \\
\text { existentes y } \\
\text { revisadas }\end{array}$ & $\begin{array}{l}\text { Alcalde, Dirección de Ase- } \\
\text { soría Legal, Departamento } \\
\text { de Medio Ambiente, Direc- } \\
\text { ción de Servicios Munici- } \\
\text { pales, y MARENA }\end{array}$ \\
\hline \multirow{2}{*}{2} & $\begin{array}{l}\text { Elaborar e implementar ordenan- } \\
\text { za para regular el manejo seguro } \\
\text { de los Residuos no peligros en el } \\
\text { ámbito municipal. }\end{array}$ & $2017-2027$ & $\begin{array}{l}\text { Aprobación de } \\
\text { Ordenanza }\end{array}$ & $\begin{array}{l}\text { Dirección de Servicios } \\
\text { Municipales, Dirección } \\
\text { Ambienta, MINSA }\end{array}$ \\
\hline
\end{tabular}




\begin{tabular}{|l|l|l|l|l|}
\hline \multicolumn{1}{|c|}{ No } & \multicolumn{1}{|c|}{ Acción } & \multicolumn{1}{c|}{ Plazo } & \multicolumn{1}{c|}{ Indicador } & \multicolumn{1}{c|}{ Responsable } \\
\hline 3 & $\begin{array}{l}\text { Desarrollar y aplicar instrumentos } \\
\text { para multas y sanciones }\end{array}$ & 2017-2027 & $\begin{array}{l}\text { Número de } \\
\text { multas al mes; } \\
\text { número de san- } \\
\text { ciones emitidas } \\
\text { al mes }\end{array}$ & $\begin{array}{l}\text { Dirección de Asesoría } \\
\text { Legal, Departamento de } \\
\text { Medio Ambiente }\end{array}$ \\
\hline 4 & $\begin{array}{l}\text { Elaborar nuevos instrumentos } \\
\text { legales relacionados al manejo de } \\
\text { residuos sólidos que a su vez con- } \\
\text { sideren incentivos para la pobla- } \\
\text { ción y trabajadores }\end{array}$ & $2017-2027$ & $\begin{array}{l}\text { Número de } \\
\text { instrumentos } \\
\text { legales aproba- } \\
\text { dos }\end{array}$ & $\begin{array}{l}\text { Alcalde, Dirección de Ase- } \\
\text { soría Legal, Departamento } \\
\text { de Medio Ambiente, Direc- } \\
\text { ción de Servicios Munici- } \\
\text { pales y MARENA }\end{array}$ \\
\hline
\end{tabular}

Tabla 4. Fortalecimiento Ecónomico

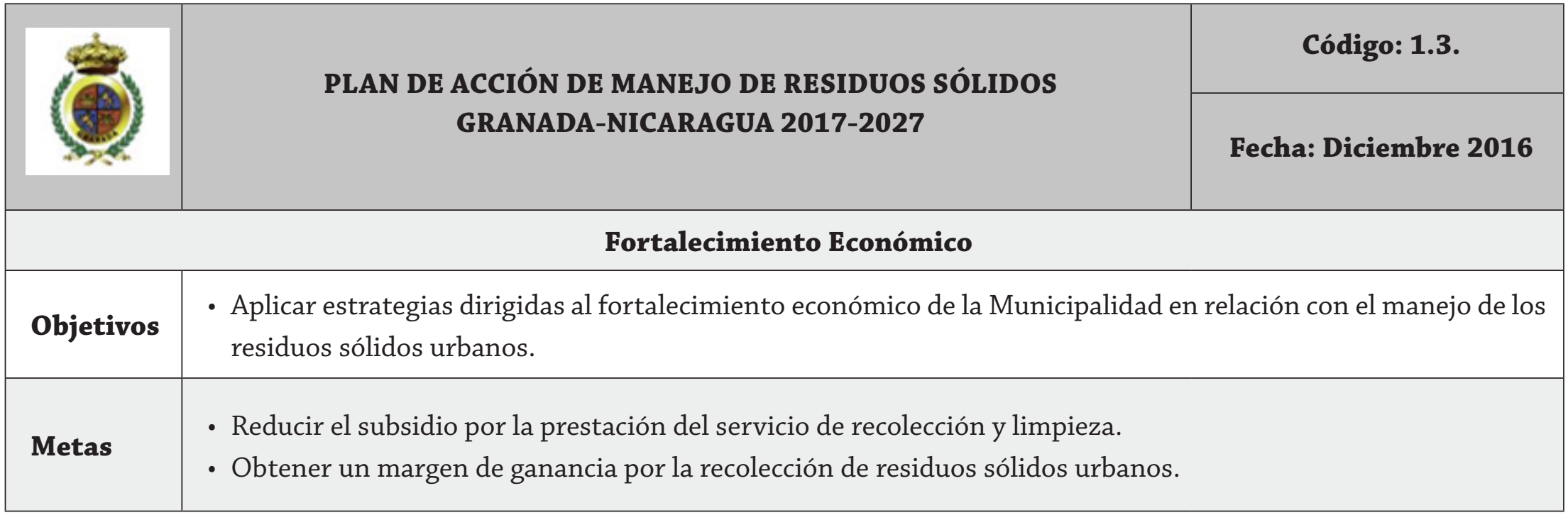




\begin{tabular}{|c|c|c|c|c|}
\hline No & Acción & Plazo & Indicador & Responsable \\
\hline 1 & $\begin{array}{l}\text { Estudio de la necesidad real exis- } \\
\text { tente del barrido de calle, con el } \\
\text { fin de determinar el número de } \\
\text { trabajadores }\end{array}$ & Cada dos Años & $\begin{array}{l}\text { Documentación } \\
\text { divulga }\end{array}$ & $\begin{array}{l}\text { Dirección de Servicios } \mathrm{Mu}- \\
\text { nicipales }\end{array}$ \\
\hline 2 & $\begin{array}{l}\text { Realizar evaluaciones de desempe- } \\
\text { ños a los recaudadores }\end{array}$ & Anual & $\begin{array}{l}\text { Infórmenos de } \\
\text { Evaluación }\end{array}$ & $\begin{array}{l}\text { Recursos Humanos y Área } \\
\text { de Contabilidad }\end{array}$ \\
\hline 3 & $\begin{array}{l}\text { Someter el Plan de Acción a la } \\
\text { mesa de cooperación con ONG's } \\
\text { e instituciones presentes en el } \\
\text { municipio o en la región }\end{array}$ & 2020-2023 & $\begin{array}{l}\text { Número de } \\
\text { organismo de } \\
\text { cooperación } \\
\text { apoyando el } \\
\text { Plan de Acción }\end{array}$ & $\begin{array}{l}\text { Alcalde, Director de Servi- } \\
\text { cios Municipales, Departa- } \\
\text { mento de Medio Ambiente, } \\
\text { ONG's, Instituciones, } \\
\text { Sector Privado }\end{array}$ \\
\hline 4 & $\begin{array}{l}\text { Desarrollar un estudio tarifario di- } \\
\text { ferenciado que se oriente a cubrir } \\
\text { el } 100 \% \text { de los gastos. Así como la } \\
\text { incorporación de la misma en el } \\
\text { pago de otros servicios. }\end{array}$ & $\begin{array}{l}\text { 2018-2019 y actuali- } \\
\text { zación bianual }\end{array}$ & $\begin{array}{l}\text { Reducción del } \\
\text { Subsidio }\end{array}$ & $\begin{array}{l}\text { Alcalde, Director de Servi- } \\
\text { cios Municipales, personal } \\
\text { de Recaudación }\end{array}$ \\
\hline
\end{tabular}


Tabla 5. Capacitación y Asistencia Técnica

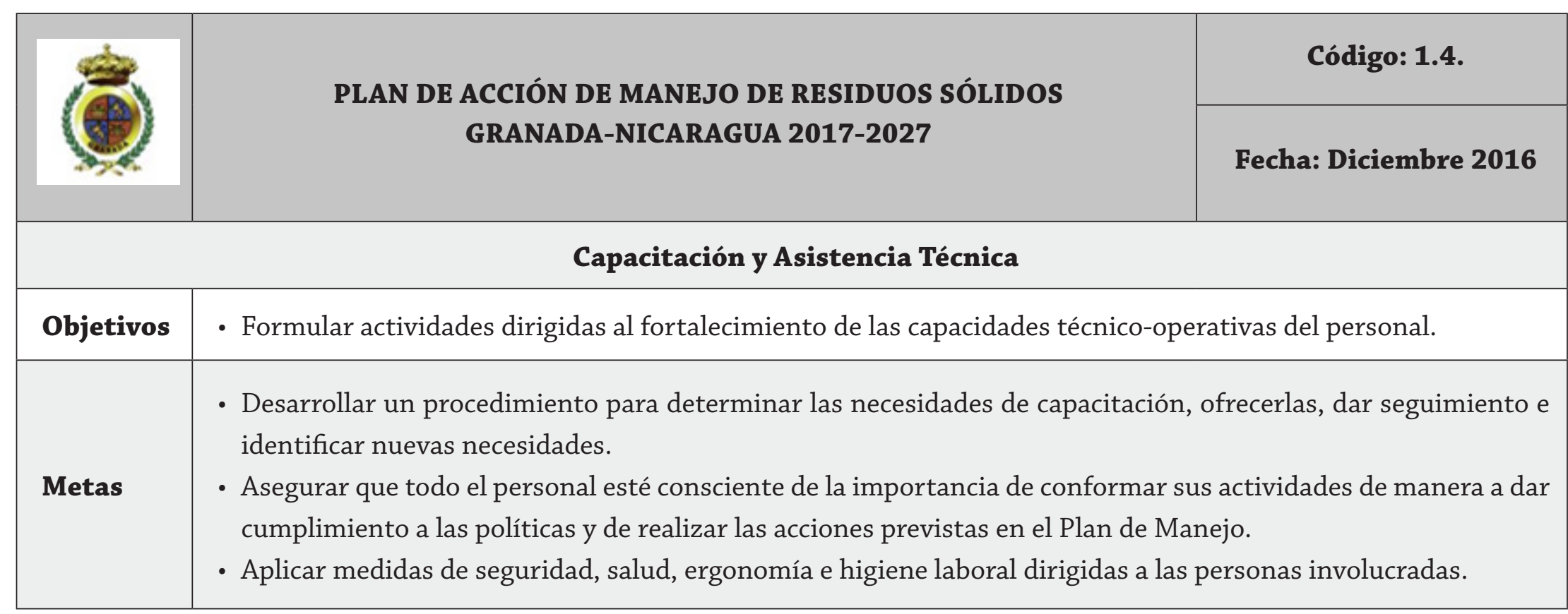

\begin{tabular}{|l|l|l|l|l|}
\hline \multicolumn{1}{|c|}{ No } & \multicolumn{1}{|c|}{ Acción } & \multicolumn{1}{c|}{ Plazo } & \multicolumn{1}{c|}{ Indicador } & Responsable \\
\hline 1 & $\begin{array}{l}\text { Asesoría para el cierre del botade- } \\
\text { ro de residuos del hospital }\end{array}$ & 2018-2020 & Plan de cierre & Dirección Ambiental \\
\hline 2 & $\begin{array}{l}\text { Capacitar en el manejos y buenas } \\
\text { prácticas de residuos especiales }\end{array}$ & Anual & $\begin{array}{l}\text { Dirección de Servicios Mu- } \\
\text { nicipales, Dirección Am- } \\
\text { bienta, MINSA y Gerencia } \\
\text { del Mercado }\end{array}$ \\
\hline 3 & $\begin{array}{l}\text { Capacitar a los recaudadores en } \\
\text { relaciones humanas }\end{array}$ & Anual & $\begin{array}{l}\text { Lista de partici- } \\
\text { pación }\end{array}$ & Recursos Humanos \\
\hline
\end{tabular}




\begin{tabular}{|l|l|l|l|l|}
\hline \multicolumn{1}{|c|}{ No } & \multicolumn{1}{|c|}{ Acción } & \multicolumn{1}{|c|}{ Plazo } & \multicolumn{1}{c|}{ Indicador } & \multicolumn{1}{c|}{ Responsable } \\
\hline 4 & $\begin{array}{l}\text { Implementar charlas de 5 minu- } \\
\text { tos antes de comenzar la jornada } \\
\text { laboral acerca de temas de me- } \\
\text { joramiento, Seguridad e higiene } \\
\text { laboral. }\end{array}$ & 2017-2019 & $\begin{array}{l}\text { Lista de Partici- } \\
\text { pación }\end{array}$ & $\begin{array}{l}\text { Dirección de Servicios Mu- } \\
\text { nicipales }\end{array}$ \\
\hline 5 & $\begin{array}{l}\text { Capacitar en seguridad, salud, } \\
\text { higiene y ergonomía laboral }\end{array}$ & Anual & $\begin{array}{l}\text { Lista de Partici- } \\
\text { pación }\end{array}$ & $\begin{array}{l}\text { Dirección de Servicios Mu- } \\
\text { nicipales }\end{array}$ \\
\hline 6 & $\begin{array}{l}\text { Solicitar asesoría en temas de } \\
\text { seguridad, salud, higiene y ergo- } \\
\text { nomía laboral }\end{array}$ & 2017-2019 & $\begin{array}{l}\text { Número de ca- } \\
\text { pacitaciones }\end{array}$ & $\begin{array}{l}\text { Alcalde, Director de Servi- } \\
\text { cios Municipales, MITRAB, } \\
\text { MINSA }\end{array}$ \\
\hline 7 & $\begin{array}{l}\text { Brindar capacitaciones técni- } \\
\text { co-operativas relacionadas al } \\
\text { manejo de los residuos sólidos }\end{array}$ & 2017- 2027 & $\begin{array}{l}\text { Capacitaciones } \\
\text { impartidas (al } \\
\text { menos 1 cada 6 } \\
\text { meses) }\end{array}$ & $\begin{array}{l}\text { Dirección de Servicios Mu- } \\
\text { nicipales }\end{array}$ \\
\hline
\end{tabular}


Tabla 6. Educación Ambiental y Participación Ciudadana

\begin{tabular}{|c|c|c|}
\hline & \multirow{2}{*}{$\begin{array}{l}\text { PLAN DE ACCIÓN DE MANEJO DE RESIDUOS SÓLIDOS } \\
\text { GRANADA-NICARAGUA 2017-2027 }\end{array}$} & Código: 1.5. \\
\hline & & Fecha: Diciembre 2016 \\
\hline \multicolumn{3}{|c|}{ Educación Ambiental y Participación Ciudadana } \\
\hline Objetivos & \multicolumn{2}{|c|}{$\begin{array}{l}\text { - Fomentar una conciencia ambiental en la población de los diferentes estratos sociales, económicos y políticos, } \\
\text { promoviendo así su participación en el manejo de los residuos sólidos. }\end{array}$} \\
\hline Metas & \multicolumn{2}{|c|}{$\begin{array}{l}\text { - Desarrollar un procedimiento formal para comunicar a la población la información relacionada al manejo de } \\
\text { los residuos sólidos urbanos. } \\
\text { - Fomentar la separación en la fuente, el re-uso y el reciclado de los diversos tipos de residuos sólidos urbanos. } \\
\text { - Incorporar a la población en la solución de los problemas asociados al mal manejo de los residuos sólidos. }\end{array}$} \\
\hline
\end{tabular}

\begin{tabular}{|l|l|l|l|l|}
\hline \multicolumn{1}{|c|}{ No } & \multicolumn{1}{|c|}{ Acción } & \multicolumn{1}{c|}{ Plazo } & \multicolumn{1}{c|}{ Indicador } & \multicolumn{1}{c|}{ Responsable } \\
\hline \multirow{3}{*}{1} & $\begin{array}{l}\text { Jornadas de información sobre } \\
\text { la tipología de los residuos que se } \\
\text { pueden depositar, las condiciones } \\
\text { y horarios establecidos. }\end{array}$ & $2017-2027$ & $\begin{array}{l}\text { Documentación } \\
\text { Aprobada y } \\
\text { divulgada }\end{array}$ & $\begin{array}{l}\text { Dirección de Servicios } \\
\text { Municipales y Dirección } \\
\text { Ambiental }\end{array}$ \\
\hline 2 & $\begin{array}{l}\text { Planificar campañas de sensibili- } \\
\text { zación y minimización en el ori- } \\
\text { gen, dirigidas a los ciudadanos que } \\
\text { incluyan buenas prácticas ambien- } \\
\text { tales y manipulación de residuos. }\end{array}$ & $2017-2027$ & $\begin{array}{l}\text { Documentación } \\
\text { Aprobada y } \\
\text { divulgada }\end{array}$ & $\begin{array}{l}\text { Dirección de Servicios } \\
\text { Municipales y Dirección } \\
\text { Ambiental }\end{array}$ \\
\hline
\end{tabular}




\begin{tabular}{|l|l|l|l|l|}
\hline \multicolumn{1}{|c|}{ No } & \multicolumn{1}{|c|}{ Acción } & \multicolumn{1}{c|}{ Plazo } & \multicolumn{1}{c|}{ Indicador } & Responsable \\
\hline \multirow{3}{*}{3} & $\begin{array}{l}\text { Convocar al sector industrial, } \\
\text { comercial y turístico para capaci- } \\
\text { taciones de buenas prácticas am- } \\
\text { bientales y una correcta gestión de } \\
\text { los residuos que generan. }\end{array}$ & 2017-2027 & $\begin{array}{l}\text { Documentación } \\
\text { Aprobada y } \\
\text { divulgada }\end{array}$ & $\begin{array}{l}\text { Dirección de Servicios } \\
\text { Municipales y Dirección } \\
\text { Ambiental }\end{array}$ \\
\hline
\end{tabular}

\section{CONCLUSIONES}

Los resultados del análisis del manejo de residuos sólidos, indica que el municipio de Granada ha ido mejorado en el manejo de los residuos sólidos, sus calles, plazas y parques se encuentran limpias; pero el municipio no cuenta con el desarrollo de estudios, propuestas de trabajo para reactivar y promover el desarrollo del manejo integral de residuos sólidos.

Existe voluntad política para la aplicación del Programa de Manejo de Residuos Sólidos pero falta una mejor articulación en el gobierno local y la sociedad civil, asimismo es necesario mejorar los niveles de conciencia ambiental a través de la educación ambiental para el manejo de los residuos sólidos.

El servicio de limpieza pública tiene problemas para lograr una cobertura óptima, debido a factores de financiamiento. Lo que si se aprecia es la existencia de capacidades humanas, tanto a nivel de la Municipalidad como en la comunidad que potenciadas pueden mejorar la situación.

\section{AGRADECIMIENTO}

Agradezco al Fondo para Proyectos de Investigación (FPI), de la UNAN-Managua por el soporte económico para la realización de esta investigación. 


\section{BIBLIOGRAFÍA}

Conesa, V., (1997). Auditorías ambientales. Guía metodológica, Madrid: Ediciones Mundiprensa.

Gutiérrez Zarruk, A; Pereira Cardenal,S. (2004). Diseño de un Plan Integral de Manejo de Residuos Sólidos en la Universidad Centroamericana(Tesis para obtener el Título de Ingeniero en Calidad Ambiental). Recuperado de: http://repositorio.uca.edu.ni/2726/1/UCANI1529.PDF

Ley General del Medio Ambiente y los Recursos Naturales No. 217 (1996, 6 de Junio) [en línea] Nicaragua: La Gaceta, Diario Oficial N . 105. Disponible: http://legislacion.asamblea.gob.ni/ Normaweb.nsf/(\$All)/1B5EFB1E58D7618A0625711600561572?OpenDocument

Mantilla Blanco, S. A. (2006). La Contabilidad y la Auditoría Ambiental. Bogotá: Ecoe Ediciones.

Norma para el Manejo y Eliminación de Residuos Sólidos Peligrosos. NTON 05 015- 01 (2002, 05 de Noviembre) [en línea] Nicaragua: La Gaceta Diario Oficial No. 210. Disponible : http:// legislacion.asamblea.gob.ni/normaweb.nsf/bbe90a5bb646d50906257265005d21f8/ f124ab4e19e485950625728a005c2c3f?OpenDocument [2016, 5 de Julio]

Norma Técnica Ambiental para el Manejo, Tratamiento y Disposición Final de los Residuos Sólidos No-Peligrosos. NTON 05 014- 02 (2002, 24 de Mayo) [en línea]. Nicaragua: La Gaceta Diario Oficial No. 96. Disponible en: http://legislacion.asamblea.gob.ni/Normaweb. nsf/(\$All)/3D7B0C9BF4C186790625764E005D16F4?OpenDocument [2016, 5 de Julio] 